\title{
CAIXEIRO VIAJANTE: APLICAÇÃO DA MODELAGEM MATEMÁTICA NA OTIMIZAÇÃO DE ROTAS EM UMA CONCESSIONÁRIA DE ENERGIA ELÉTRICA
}

\section{TRAVELING SALESMAN: APPLYING MATHEMATICAL MODELING IN THE OPTIMIZATION OF ROUTES IN A CONCESSIONARY OF ELECTRICAL ENERGY}

\author{
Ivanilda Agustinho Ferreira* E-mail: i ivanilda@hotmail.com \\ * Universidade Federal da Paraíba (UFPB), João Pessoa, PB
}

\begin{abstract}
Resumo: Este artigo apresenta um estudo de caso em uma concessionária de distribuição de energia elétrica brasileira com o objetivo de realizar uma aplicação sobre o Problema do Caixeiro Viajante (PCV). Visando otimizar as rotas das equipes de manutenção de subestações através da disponibilização de coordenadas do Google Maps das respectivas unidades consumidoras (UC) das subestações de um determinado estado. Essa otimização de rotas foi modelada utilizando o Problema do Caixeiro Viajante (PCV), juntamente com o Visual Basic for Applications (VBA) e o UFFLP integrado ao Microsoft Excel 2007. Com o intuito que as equipes de manutenção percorram o caminho de menor distância entre as possíveis subestações a serem visitadas, com a finalidade de executarem suas ordens de serviços. Desde que a equipe de manutenção, saísse primeiramente da sede da concessionária, percorresse as subestações estabelecidas e retornasse no final para a sede, sem existir a possibilidade de passar mais de uma vez na mesma subestação denominada de cliente, correspondendo assim, a melhor rota encontrada quando comparada com a sequência estabelecida inicialmente pela concessionária. Portanto, os gráficos e as figuras permitiram uma interpretação objetiva e notório sobre os dados e resultados dos indicadores de performance. Essa otimização contribui na redução do tempo gasto em deslocamentos, resultando em uma disponibilidade em mão de obra para executarem outras atividades. Influência também no aumento de indicadores de desempenho por equipe, além de diminuir os custos relacionados à manutenção dos veículos.
\end{abstract}

Palavras-chave: Problema do Caxeiro Viajante. Equipes de manutenção. UFFLP. Visual Basic. Rotas.

\begin{abstract}
This article presents a case study in a Brazilian electricity distribution concessionaire with the objective of realizing an application about the Traveling Salesman Problem (PCV). Aiming to optimize the routes of substation maintenance teams through the availability of Google Maps coordinates of the respective consumer units $(\mathrm{UC})$ of the substations of a given state. This route optimization was modeled using the Traveling Clerk Problem (PCV) along with Visual Basic for Applications (VBA) and the UFFLP integrated with Microsoft Excel 2007. In order for maintenance teams to travel the shortest path between the possible substations to be visited, in order to execute their service orders. As long as the maintenance team leaves first of the concessionaire headquarters, it goes through the established substations and returns at the end to the headquarters, without being able to spend more than once in the same substation called customer, corresponding, thus, the best route found when compared to the sequence initially established by the concessionaire. Therefore, the graphs and the figures allowed an objective and notorious interpretation on the data and results of the performance indicators. This optimization contributes to the reduction of the time spent on commuting, resulting in an availability of labor to carry out other activities. Influence also on the increase of indicators of performance per team, besides reducing the costs related to the maintenance of the vehicles.
\end{abstract}

Keywords: Traveler Clerk Problem. Maintenance teams. UFFLP. Visual Basic. Routes. 


\section{INTRODUÇÃO}

A globalização confere impactos que resultam nas expansões de mercado em escala mundial, exigindo que as empresas busquem aperfeiçoar e gerenciar seus processos para almejar uma parcela significativa do mercado. Este cenário, requisita que as empresas forneçam serviços com qualidade aos seus clientes, ao mesmo tempo em que desenvolvam estratégias de economizar e superar os desafios do cotidiano. As empresas que utilizam veículos para prestar serviços possuem o deslocamento como uma atividade totalmente necessária ao seu processo interno. Assim, a utilização de softwares e aplicativos integrados ao Google Maps são possibilidades de otimizar estas possíveis rotas. Porém, a aquisição ou desenvolvimento de software de roteamento de veículos torna-se caro, devido à disposição dos recursos financeiros de empresas. E na maioria das vezes não traduzem a totalidade da realidade dos processos da empresa. Para tanto, existe uma maneira acessível, mediante a utilização do Solver do Microsoft Excel para resolver problemas de programação linear.

O tempo de deslocamento das equipes influência na disponibilidade para executar serviços que agregam valor ao processo de manutenção em subestações. Os deslocamentos desnecessários entre as subestações e a sede da concessionária de energia elétrica impactam na performance de indicadores, necessariamente na métrica produtividade. Quando as equipes se deslocam para campo, fazendo uso de um percurso longo, ao final do dia correm o risco de não cumprirem toda a sua respectiva programação de manutenção semanal recebida e originada no Planejamento e Controle da Manutenção (PCM) anual. Este fato poderá acarretar na postergação das demais atividades da programação, sendo necessário possuir mais mão de obra para compor equipes, bem como geração de horas extras e gastos adicionais, uma vez que, existe uma vasta faixa de subestações a serem inspecionadas.

Como o deslocamento é contabilizado como uma métrica improdutiva, ou seja, quanto maior os valores gastos com deslocamentos, menor é a probabilidade de alcançar o indicador produtividade na concessionária. Portanto, este artigo mediante 
a implementação do modelo do problema do caixeiro viajante (PCV) visa minimizar distâncias percorridas pelas equipes.

\section{MATERIAIS E MÉTODOS}

\subsection{Problema do Caxeiro Viajante}

O Problema do Caixeiro Viajante consiste em um problema onde existe um conjunto de cidades, um ponto de partida e um caixeiro. Esse caixeiro sai desse ponto de partida (sede) visita todas as cidades ou um subconjunto de cidades somente uma única vez e retorna ao ponto de partida visando otimizar determinada situação.

Segundo Arenales et. al. (2007) problemas de caixeiro viajante pertencem à classe de problemas de roteamento de nós, e são definidos em grafos orientados ou não orientados.

Os grafos são constituídos pela união de dois conjuntos $(\mathrm{V}, \mathrm{A})$. Onde $\mathrm{V}$ é um conjunto não vazio que representa os vértices ou os nodos do grafo. $E$ o conjunto $A$ de pares ordenados representam as arestas do grafo. Exemplificando mediante a utilização da figura 1, considere o grafo $G(c, A)$, onde c é o conjunto de nós de $G$, que representam as 10 cidades e $A$ o conjunto dos arcos de $G$, que representa a conexão entre cidades. Os arcos na figura 1 representam as possibilidades de rotas entre apenas 10 cidades escolhidas, ou seja, menor distância.

Assim, cada subconjunto de vértices deste grafo contém as $\mathrm{n}$ cidades consideradas, e os custos para a designação de cada par de cidades representam a distância Euclidiana ou o custo da viagem entre estas cidades (SIQUEIRA, 2005).

O problema do caixeiro viajante apresenta algumas variações com relação ao objetivo final de otimização, podendo ser distância, custos, e aquisição de produtos. Entretanto, o enfoque deste artigo está no problema mais clássico e mais importante, que trata da minimização da distância percorrida entre as subestações de energia elétrica.

Segundo Caixeiro (2000) o problema do caixeiro é um clássico exemplo de problema de otimização combinatória. E consiste em descobrir a rota que torna mínima a viagem total. 
Figura 1 - Grafo do problema com 10 nós

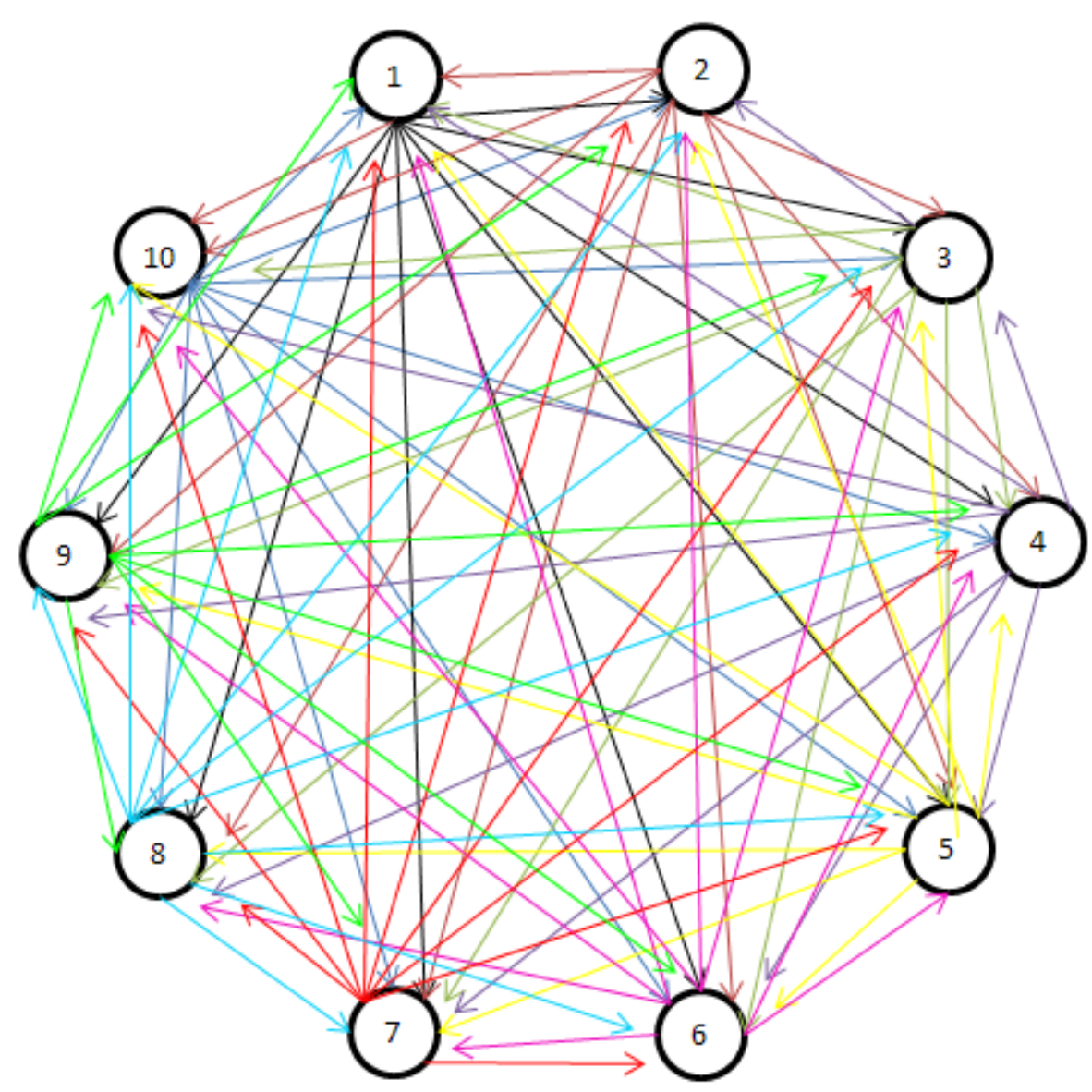

Fonte: Autora (2018)

De acordo com Lachtermacher (2007), representa um caso especial de problemas de redes, em que os arcos significam a distância entre dois pontos (nós). Quando desejamos achar a rota que une estes pontos com distância mínima entre as possíveis, teremos um problema do tipo do menor caminho. Este tipo de problema pode ser generalizado e aplicado à distribuição de energia, e entre outros.

Em problemas de menor caminho haverá sempre dois tipos de nós especiais chamados de origem e destino. A modelagem do problema terá variáveis binárias do tipo Xij indicando o sentido da cidade i para a Cidade j. Se o valor da variável for igual a um, significa que aquele trecho deve ser percorrido. De forma inversa, se o valor da variável for igual à zero, a estrada que liga a cidade i à cidade j não deverá ser utilizada.

A função-objetivo visa minimizar a distância percorrida [...]; logo, se as variáveis de decisão assumem zero ou um, a multiplicação destas pelas distâncias entre as respectivas cidades será zero e igual à distância entre as cidades se esta for utilizada (LACHTERMACHER, 2007, p.143). 


\subsection{Roteamento de Veículos}

Roteamento de veículos está intrinsicamente interligado com a sua relevância, ou seja, é de grande importância para indústrias, e este último interfere na economia mundial. Nesse sentido, vale salientar que o estudo de Roteamento de Veículos se dá pela caracterização dos seus problemas meramente existentes. Com isso, é importante descrever alguns dos principais problemas que são encontrados no Roteamento de Veículos (MANGUINO, 2013).

Um dos principais problemas de Roteamento de Veículos é o VRP, conhecido como (Vehicle Routing Problem - VRP), tem como objetivo principal encontrar rotas, a partir de um ponto principal, ou armazém central, com veículos iguais, com menor custo possível para atender a demanda e principalmente as necessidades dos clientes (MANGUINO, 2013).

Porém, o VRP, não é o único problema existente, pois os autores Toth e Vigo (2002), apontam que os veículos para transporte de mercadorias enfrentam o principal problema de mudança de rota, pois os transportes de produtos é feito para atender as necessidades específicas dos clientes, e estes são caracterizados para tal fim, por isso o problema existente do veículo não retornar para o deposito original gera um problema com maior grau de ser solucionado.

Coelho (2010) aponta que existem outras variações de problemas, tais como o problema de Roteamento com janelas de tempo e Roteamento com múltiplos depósitos, no entanto, estes últimos representam boa parte das pesquisas e dos casos práticos utilizados.

Contudo, o autor anterior, relata que, assim como no Problema do Caixeiro Viajante, o roteamento de veículos também é solucionado através de heurísticas, os métodos "inteligentes" que geram boas soluções em um tempo reduzido. E isto está em concordância com o pensamento de Marque et al. (2005), que a solução dos problemas encontrados no Roteamento de Veículos depende do método proposto, de tal maneira a minimizar o tempo, custo, utilização de veículos, de formar a equilibrar todos estas opções durante toda operação logística.

Para Pisinger e Ropke (2007), levando em consideração todos os aspectos que tornam o problema de roteamento de veículos complicado de ser resolvido, é possível 
propor metas para solucionar o problema. A primeira refere-se em minimizar o custo de transporte global, que depende da distância global viajada, ou do tempo total viajado, além dos custos associados com os veículos usados para o transporte e o custo do motorista.

\subsection{UFFLP e Visual Basic Applications}

O UFFLP é definido como um conjunto de funções pertencentes a diversos softwares, cujo principal objetivo é resolver modelos de programação. Sua utilização se tornou popular pelo fato de estar disponível dentro das planilhas do Microsoft Excel, facilitando os tratamentos de dados de modelos matemáticos através das linguagens VBA (GAPSON, 2018).

O UFFLP foi criado para atender a demanda de profissionais que utilizam tais sistemas, incluindo os estudantes, engenheiros e professores. A UFFLP tem em seu conjunto diversas funções em $\mathrm{C} / \mathrm{C}++$ ou VBA que são manipuláveis, e com isso, UFFLP tem em seu suporte os resolvedores CPLEX e GUROBI, gratuitos para uso acadêmico, COIN CBC e CLPK, e com código de fonte aberto (GAPSON, 2018).

Em semelhança ao UFFLP, o Visual Basic é caracterizado por também ser um programa de linguagem de programação. Foi produzida pela Empresa Microsoft pertencente ao pacote Microsoft Visual Basic. O Visual Basic tem inúmeros recursos que possibilita a otimização de tarefas específicas, além do que permite a interação com outros softwares (AIOSA, 2011).

O uso de comandos VBA se faz necessário quando se almeja realizar tarefas complexas. Este comando será responsável por auxiliar o usuário na busca de valores em determinados locais da planilha do Excel, além de possibilitar a visualização da sequência de dados dispostos em dada linha e/ou coluna (PARANHOS, 2013).

\subsection{Manutenção em Subestações}

A manutenção é considerada uma prática habitual em muitas empresas e conferem-Ihes confiabilidade e segurança em sistemas de máquinas para garantir sucesso em suas operações. É imprescindível para o gerenciamento de processos, 
pois auxilia a implementar ações e estratégias benéficas com o intuito de evitar o surgimento de não conformidades que acarretem em transtornos gerenciais e custos adicionais.

A ausência de manutenção ou até mesmo um plano de manutenção ineficiente favorece que o processo aponte variações e falhas inesperadas exigindo que os responsáveis devam implementar modelos gerências de manutenção adequados com sua realidade, para assegurar a qualidade da prestação do serviço.

No caso do setor elétrico, a manutenção preventiva, preditiva e corretiva favorece a redução de interrupção de energia elétrica devido a falhas em linhas de transmissões, subestações de energia elétrica, componentes e equipamentos, impossibilitando o surgimento de multas de órgãos regulamentadores de energia.

"Manutenção combinação de todas as ações técnicas e administrativas, incluindo as de supervisão, destinadas a manter ou recolocar um item em um estado no qual possa desempenhar uma função requerida" (NBR ISO-8402, 1994, p.6).

Segundo a NBR 5462 - Confiabilidade e Mantenabilidade, as definições para as principais atividades ou metodologias de atuação da manutenção são:

- Manutenção Corretiva: Manutenção efetuada após a ocorrência de uma pane destinada a recolocar um item em condições de executar uma função requerida;

- Manutenção Preventiva: Manutenção efetuada em intervalos predeterminados, ou de acordo com critérios prescritos, destinada a reduzir a probabilidade de falha ou a degradação do funcionamento de um item;

- Manutenção controlada/Manutenção preditiva: Manutenção que permite garantir uma qualidade de serviço desejada, com base na aplicação sistemática de técnicas de análise, utilizando-se de meios de supervisão centralizados ou de amostragem, para reduzir ao mínimo a manutenção preventiva e diminuir a manutenção corretiva;

- Manutenção programada: Manutenção preventiva efetuada de acordo com um programa preestabelecido;

- Manutenção não programada: Manutenção que não é feita de acordo com um programa preestabelecido, mas depois da recepção de uma informação relacionada ao estado de um item. 
Logo, a manutenção confere vantagens competitivas perante os demais concorrentes, redução de despesas e tempo disponível que agrega valor ao processo final. Existem diversos tipos de manutenção, cabe saber qual é a mais apropriada para a gestão do negócio da empresa.

\subsection{Indicador Produtividade}

Devido à expansão da tecnologia, podemos considerar a existência de um cenário bastante competitivo com a predominância de relações mercadológicas em diversos países, sem a restrição de fronteiras. Por sua vez, para que as empresas tenham vantagens competitivas, torna-se necessário adotar conceitos e fazer uso de ferramentas de gerenciamento de qualidade, receber consultorias, utilizar softwares para gerenciar o sistema de informação gerencial e outras técnicas e estratégias.

Uma das metodologias existentes para inserir a empresa no mercado competitivo é passar a mensurar a sua produtividade com a finalidade de identificar o real esforço. O termo produtividade "[...] foi utilizado pela primeira vez, de maneira formal, em um artigo do economista francês Quesnay, em 1766". "[...] em 1883, outro economista francês, Littre, o utilizou com o sentido de capacidade para produzir". Logo, "[...] no começo do século XX, o termo assumiu o significado da relação entre o produzido (output) e os recursos empregados para produzi-lo (input)" (MARTINS; LAUGENI, 2015, p. 11).

Espera-se que os processos existentes nas empresas obtenham um número elevado de bens e produtos com o mínimo dos elementos de entradas, tais como, recursos, mão de obra, energia. Assim, "[...] a produtividade depende essencialmente do output, ou seja, o numerador da fração, e do input, o denominador" (MARTINS; LAUGENI, 2015, p. 9).

Porém, torna-se relevante expor os conceitos de eficiência e eficácia para compreender a definição e produtividade.

Eficácia: medida de quão próximo se chegou dos objetivos previamente estabelecidos. Assim, uma decisão ou ação é tanto mais eficaz quanto mais próximos dos objetivos estabelecidos chegarem os resultados obtidos. Eficiência: relação entre o que se obteve (output) e o que se consumiu em sua produção (input), medidos na mesma unidade" (MARTINS; LAUGENI, 2015, p. 10). 
Assim, a produtividade se relaciona com o termo eficiência, que indica esforço produtivo.

\subsubsection{Medidas de produtividade}

Segundo Martins e Laugeni (2015), existem inúmeras maneiras de mensurar a produtividade e cada uma possui vantagens e desvantagens. Porém, todos são iguais no que se refere aos benefícios decorrentes do aumento da produtividade, tais como: aumento no lucro, maiores salários, preços baixos e impactos positivos no nível de vida da sociedade. Entretanto, a mais aceita refere-se à utilização de indicadores, que possibilitam avaliar as variações ao longo do tempo de uma grandeza não suscetível de medida direta.

Logo, a "produtividade parcial: relação entre o que foi produzido e o consumido de um dos insumos (recursos) utilizados. Assim, produtividade da mão de obra ou do capital é uma medida de produtividade parcial" (MARTINS; LAUGENI, 2015, p. 11). Conforme a fórmula a seguir:

$$
P P_{i}=\frac{\text { output }}{\text { input }_{i}}
$$

Onde: input $t_{i}$ é input do insumo $i$.

A produtividade total pode ser avaliada da seguinte maneira:

$$
P T=\frac{\text { output }}{\text { input }}
$$

"A produtividade é, portanto, uma avaliação realizada entre dois instantes no tempo. Assim, faz sentido referir-se à produtividade no dia, no mês, no ano. Em consequência, a variação dela é avaliada entre dois períodos, consecutivos ou não" (MARTINS; LAUGENI, 2015, p. 18).

A produtividade confere avaliar o sistema de produção, ou seja, refere-se a medir a relação entre as entradas e as saídas resultantes.

\subsubsection{Métrica}

Para Martins e Laugeni (2015), a métrica corresponde ao número resultante de uma contagem, uma medição, ou calculado por meio de critério previamente 
estabelecido para os casos em que o objeto de estudo não é mensurável e deve possuir as seguintes características:

- Estar alinhada com os objetivos estratégicos da empresa;

- $\quad$ Ser de fácil cálculo e compreensão por todos os colaboradores envolvidos;

- $\quad$ Fornecer feedback para ações corretivas;

- Ser tecnicamente consistente, ou seja, ordenar duas situações de forma inequívoca;

- $\quad$ Ser importante;

- $\quad$ Ter propósito definido;

- $\quad$ Facilitar melhoria nos processos e não somente os monitorar.

\subsubsection{Métrica OEE}

OEE é considerado uma métrica largamente utilizada em empresas para mensurar a eficiência global e significa Overall Equipment Efficiency. A partir dessa métrica é possível obter ganhos relacionados à eficiência de sistemas de máquinas bem como obter ganhos e melhorias contínuas em seus respectivos processos produtivas.

Segundo Martins e Laugeni (2015), a métrica OEE pode ser obtida a partir das denominadas seis tipos de perdas: 1- quebras; 2- ajustes (setup); 3- pequenas paradas/tempo ocioso; 4- baixa velocidade; 5- qualidade insatisfatória; 6 - perdas com startup. Mediante essas perdas, é possível calcular o Índice de Disponibilidade (ID), Índice de Eficiência (IE), Índice de Qualidade (IQ) e a métrica OEE a seguir:

Índice de Disponibilidade:

$$
I D=\frac{T O}{T T D}
$$

Onde:

- TO: Tempo de Operação;

- $\quad$ TTD: Tempo Total Disponível;

- $\quad$ TTD: (Disponibilidade possível) - (Paradas programadas);

- TO: TTD - (Perda $1+$ Perda 2) 
As perdas 3 e 4 definem o IE:

$$
I E=\frac{T O-(\text { Perda } 3+\text { Perda } 4)}{T O}
$$

As perdas 5 e 6 definem o IQ:

$$
I Q=\frac{\text { Quantidade de itens produzidos }-(\text { Perda } 5+\text { Perda } 6)}{\text { Quantidade de itens produzidos }}
$$

A métrica OEE é calculada da seguinte forma:

$$
O E E=I D \times I E \times I Q
$$

Assim, as métricas mensuram o presente cenário das equipes objetivando um posicionamento coerente com a realidade da empresa.

\subsection{Mapa Conceitual}

Entre o setor de energia elétrica e a sociedade, as concessionárias que atuam como agente institucional funciona como elo, visto que as instalações existentes recebem das companhias de transmissão todo o suprimento destinado ao abastecimento no país. Logo, a Figura 02, representa percurso da energia elétrica nas redes de transmissão, após deixar a usina, percorrer em tensão que varia de $88 \mathrm{kV}$ (quilovolts) a $750 \mathrm{kV}$. Quando atingem às subestações das distribuidoras, a tensão por sua vez é rebaixada e, por meio de um pequeno sistema compreendido por postes, transformadores e fios chegam à unidade final, como residências, em 127 volts ou 220 volts. Porém, a tensão não é rebaixada para determinadas unidades industriais, pois necessitam operar com tensões mais elevadas (de 2,3 kV a $88 \mathrm{kV}$ ) em suas linhas de produção e devido a isto, recebem energia elétrica diretamente da subestação da distribuidora através de redes de subtransmissões, correspondendo ao percurso realizado pela energia elétrica até as unidades consumidoras (ANEEL, 2008). 
Figura 02 - Percurso da ENEL

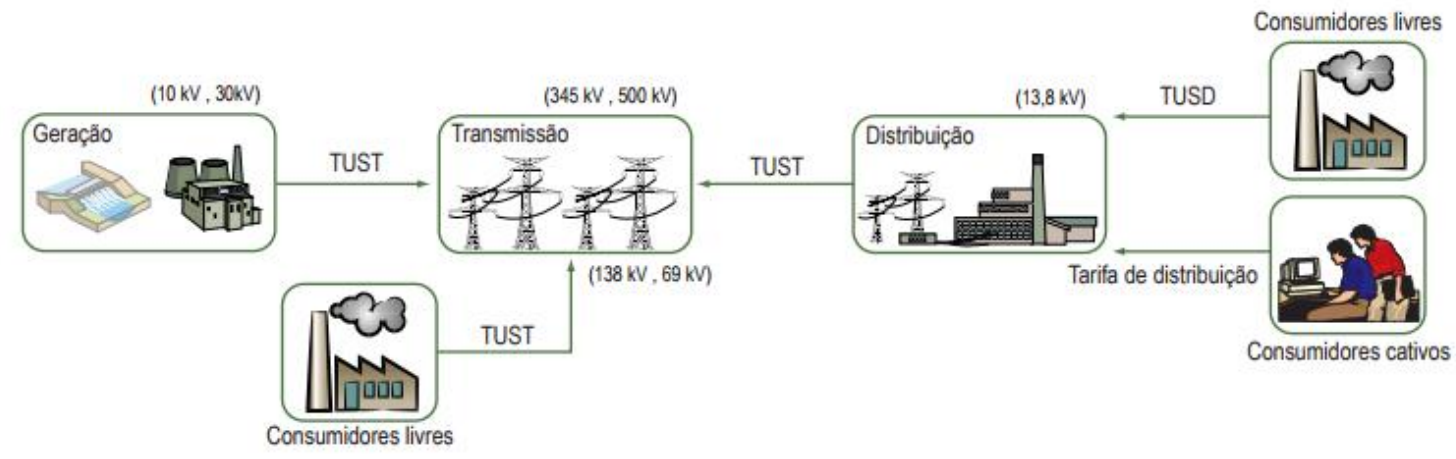

Fonte: ANNEL (2008)

O fornecimento de ENEL é um dos serviços mais desafiantes da sociedade moderna. Para que o consumidor disponha de energia no momento que aciona um interruptor ou conecta um aparelho elétrico na tomada, é preciso que um vasto aparato, como por exemplo, centrais geradoras, linhas de transmissões, subestações e linhas e transformadores de distribuição, no qual estejam aptos a operar de forma coordenada (SALES et al, 2014).

Com o intuito de melhor descrever o procedimento rotineiro das equipes de manutenção de subestações, faz necessário uso do mapa conceitual. Este corresponde uma ferramenta que auxilia a apresentação esquemática como as equipes, se orientam para realizarem suas rotinas. Mediante experiências e conhecimentos inerentes a profissão e a rotina são capazes de conduzir com a execução das atividades pré-estabelecidas nas ordens de serviços. Influenciando diretamente na assimilação global do processo existente, através da verificação dos recursos utilizados e das variáveis atuantes.

Para Tavares (2007), o mapa conceitual pode ser considerado uma estrutura esquemática para mostrar um conjunto de conceitos existentes em uma rede de proposições, considerado como um estruturador do conhecimento, na medida em que permite mostrar como o conhecimento sobre determinado tema está disposto na estrutura cognitiva de seu autor, que assim pode visualizar e analisar a sua profundidade e a extensão.

A Figura 03 representa um mapa conceitual tipo fluxograma. "Ele organiza a informação de uma maneira linear. Ele é utilizado para mostrar passo a passo determinado procedimento, e normalmente inclui um ponto inicial e outro ponto final" (TAVARES, 2007, p. 5). 


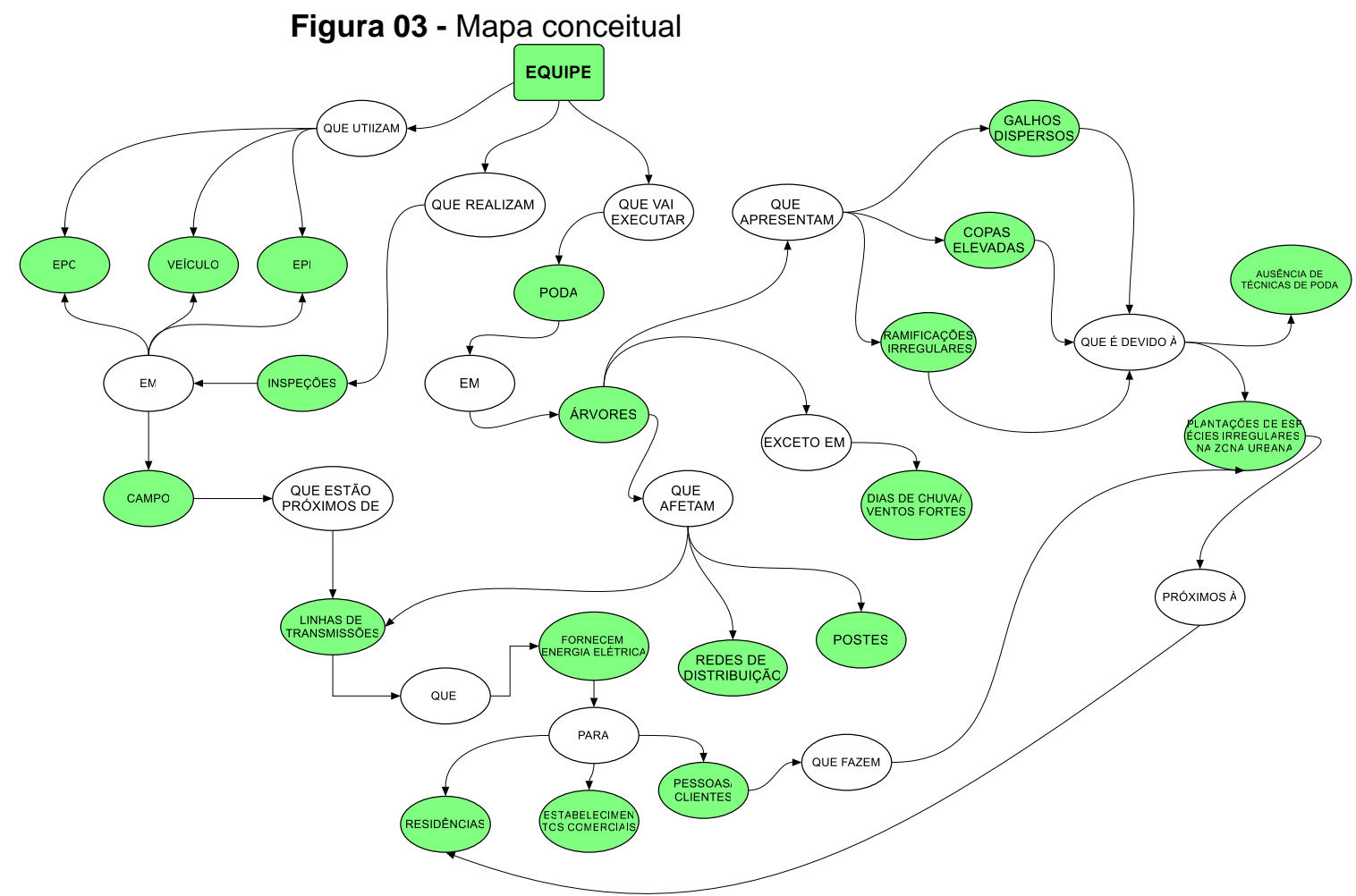

Fonte: Autora (2018)

Os principais serviços de manutenção realizados pelas equipes podem ser de origem corretiva, preventiva e preditiva, ou seja, manutenção em equipamentos, retiradas de pontos quentes, inspeções visuais de patrulhamento, substituição de equipamentos, comissionamento, realização de podas em árvores, obras, melhorias, coleta de óleo de transformadores para fazer análises físico-químicas.

De fato, para executar de forma satisfatória a programação de serviços, tornase necessário que os responsáveis pelas equipes e pela gestão da manutenção possam trabalhar de forma integrada, possibilitando o deslocamento de equipe até a subestação pela melhor rota.

\section{METODOLOGIA}

O presente artigo possui o objetivo de implementar o modelo do problema do Caixeiro viajante (PCV) em um determinado setor específico de uma concessionárias de energia elétrica, com o intuito de propor rotas com menores distâncias possíveis, visualizando a minimização do deslocamento total.

Os dados foram coletados de forma quantitativa, utilizando as coordenadas latitude e longitude geográficas disponibilizadas pelo Google Maps. Depois foram 
convertidas de grau para o formato decimal, de 29 subestações incluindo a sede, considerada como ponto de origem e inseridas no GMaps para gerar a matriz de deslocamentos assimétrica.

A tabela 1 representa as coordenadas das cidades, incluindo a sede com a numeração representada pelo número 1.

Posteriormente foi possível gerar uma matriz de deslocamento em quilômetro por hora conforme Figura 4, que consistiria no banco de dados de onde seriam extraídas as informações para implementação da modelagem matemática.

Tabela 1 - Coordenadas dos clientes

\begin{tabular}{|c|c|c|c|c|}
\hline Clientes & Latitude & Longitude & $\begin{array}{l}\text { Latitude } \\
\text { decimal }\end{array}$ & $\begin{array}{c}\text { Longitude } \\
\text { decimal }\end{array}$ \\
\hline 1 & 7010’02.30" S & 34ํ52'37.52" W & $-7,167307$ & $-34,877092$ \\
\hline 2 & $7^{\circ} 05^{\prime} 13.70^{\prime \prime} \mathrm{S}$ & $34^{\circ} 51^{\prime} 00.18^{\prime \prime} \mathrm{W}$ & $-7,087140$ & $-34,850053$ \\
\hline 3 & 7-30'48.19" S & 345'ㄴ'22.82" W & $-7,513386$ & $-34,889675$ \\
\hline 4 & $7^{\circ} 01 ' 38.08^{\prime \prime} \mathrm{S}$ & $34^{\circ} 50^{\prime} 23.65^{\prime \prime} \mathrm{W}$ & $-7,027246$ & $-34,839903$ \\
\hline 5 & 7015'43.93" S & $34 \div 56^{\prime} 14.01 " \mathrm{~W}$ & $-7,262204$ & $-34,937227$ \\
\hline 6 & $7^{\circ} 07^{\prime} 05.44^{\prime \prime} \mathrm{S}$ & 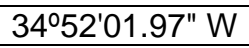 & $-7,118178$ & $-34,867217$ \\
\hline 7 & 7014'23.83" S & $34^{\circ} 55^{\prime} 45.81^{\prime \prime} \mathrm{W}$ & $-7,239954$ & $-34,929394$ \\
\hline 8 & 7ำ13'17.06" S & 3501'53.10" W & $-7,221408$ & $-35,031418$ \\
\hline 9 & 659'04.47" S & 3502'10.18" W & $-6,984575$ & $-35,036161$ \\
\hline 10 & $7^{\circ} 29^{\prime} 34.67^{\prime \prime} \mathrm{S}$ & $35^{\circ} 02^{\prime} 16.20 " \mathrm{~W}$ & $-7,492965$ & $-35,037836$ \\
\hline 11 & 7ㅇ1ㅇ'49.62" S & $34 \div 54^{\prime} 25.05^{\prime \prime} \mathrm{W}$ & $-7,180451$ & $-34,906959$ \\
\hline 12 & $7^{\circ} 08^{\prime} 49.53^{\prime \prime} \mathrm{S}$ & $34 \div 59^{\prime} 17.67 " \mathrm{~W}$ & $-7,147094$ & $-34,988243$ \\
\hline 13 & $7^{\circ} 07^{\prime} 51.98^{\prime \prime} \mathrm{S}$ & 34ㅇㄴ'15.97" W & $-7,131106$ & $-34,904436$ \\
\hline 14 & 7020'19.62" S & 3520'18.40" W & $-7,338786$ & $-35,338445$ \\
\hline 15 & 6-37'26.40" S & $35^{\circ} 16^{\prime} 54.41^{\prime \prime} \mathrm{W}$ & $-6,624002$ & $-35,281781$ \\
\hline 16 & 7은ㄷ․6. S S & $344^{\circ} 52$ '04.11" W & $-7,129625$ & $-34,867809$ \\
\hline 17 & 6ొ59'41.38" S & $34 \div 54 ' 27.51 " \mathrm{~W}$ & $-6,944828$ & $-34,907643$ \\
\hline 18 & 6035'35.72" S & $35^{\circ} 03 ' 32.32^{\prime \prime} \mathrm{W}$ & $-6,593257$ & $-35,058978$ \\
\hline 19 & 7은'ㄹ.13" S & 34ㅇํ'12.76" W & $-7,161704$ & $-34,820211$ \\
\hline 20 & 7응ㄷㄴ.27" S & $34 \div 50 ' 50.95^{\prime \prime} \mathrm{W}$ & $-7,099243$ & $-34,847487$ \\
\hline 21 & $7^{\circ} 20^{\prime} 05.43^{\prime \prime} \mathrm{S}$ & $34 \div 57^{\prime} 03.25 " \mathrm{~W}$ & $-7,334842$ & $-34,950905$ \\
\hline 22 & 7ㅇ1'48.84" S & $34^{\circ} 53^{\prime} 38.32 " \mathrm{~W}$ & $-7,180235$ & $-34,893978$ \\
\hline 23 & $7^{\circ} 23^{\prime} 09.07^{\prime \prime} \mathrm{S}$ & $35^{\circ} 08^{\prime} 54.86^{\prime \prime} \mathrm{W}$ & $-7,385855$ & $-35,148573$ \\
\hline 24 & 7012'39.95" S & $34 \div 49^{\prime} 43.81^{\prime \prime} \mathrm{W}$ & $-7,211099$ & $-34,828839$ \\
\hline 25 & 6048'56.51" S & 3506'03.85" W & $-6,815699$ & $-35,101072$ \\
\hline 26 & 70ㅜㄴ'13.77" S & 35-13'20.15" W & $-7,087160$ & $-35,222266$ \\
\hline 27 & $7^{\circ} 07^{\prime} 04.10^{\prime \prime} \mathrm{S}$ & $34^{\circ} 57^{\prime} 46.87^{\prime \prime} \mathrm{W}$ & $-7,117807$ & $-34,963022$ \\
\hline 28 & $7^{\circ} 06^{\prime} 55.34^{\prime \prime} \mathrm{S}$ & $34^{\circ} 50^{\prime} 03.18^{\prime \prime} \mathrm{W}$ & $-7,115374$ & $-34,834218$ \\
\hline 29 & 7은'09.32" S & 3505'20.25" W & $-7,585923$ & $-35,08896$ \\
\hline
\end{tabular}

Fonte: Autora (2018) 
Figura 4 - Matriz de distância em Km/h

\begin{tabular}{|c|c|c|c|c|c|c|c|c|c|c|c|c|c|c|c|c|c|c|c|c|c|c|c|c|c|c|c|c|}
\hline \multirow[b]{2}{*}{ Cidades } & \multicolumn{28}{|c|}{ Matriz de Dados - Distância KM } \\
\hline & 1 & 2 & & 4 & 5 & 6 & 7 & 8 & 9 & 10 & 11 & 12 & 13 & 14 & 15 & 16 & 17 & 18 & 19 & 20 & & 22 & 23 & 24 & 25 & 26 & 27 & \\
\hline 1 & & $\frac{2}{17,06}$ & 57,92 & $\frac{4}{22,55}$ & $\frac{5}{16,62}$ & 7,19 & $\frac{1}{14,20}$ & 31,08 & 36,70 & $\frac{10}{58,58}$ & $\frac{11}{7,38}$ & $\frac{12}{17,70}$ & $\frac{13}{12,14}$ & $\frac{14}{69,93}$ & 88,94 & $\frac{10}{5.99}$ & $\frac{18}{41,39}$ & 95,80 & $\frac{19}{10,78}$ & $\frac{20}{12,44}$ & $\frac{21}{25,39}$ & $\frac{22}{7,60}$ & 53,82 & 12,76 & 57,61 & 59,72 & $\frac{21}{14,51}$ & $\frac{28}{12,14}$ \\
\hline 2 & 12,23 & & 68,08 & 9,69 & 26,78 & 6,66 & 24,36 & 41,24 & 46,86 & 68,74 & 17,54 & 27,86 & 10,34 & 80,09 & 99,10 & 10,55 & 51,55 & 105,96 & 16,57 & 6,42 & 35,55 & 17,76 & 63,98 & 20,44 & 67,77 & 69,88 & 24,67 & 6,12 \\
\hline 3 & 54,01 & 68,27 & & 73,75 & 40,12 & 58,34 & 44,71 & 78,11 & 83,73 & 26,85 & 50,56 & 64,73 & 59,17 & 78,78 & 135,97 & 57,17 & 88,42 & 142,83 & 67,57 & 63,65 & 37,55 & 49,97 & 56,04 & 49,55 & 104,64 & 106,75 & 61,54 & 63,34 \\
\hline 4 & 18,98 & 7,13 & 74,84 & & 33,53 & 13,42 & 31,11 & 48,00 & 53.62 & 75,50 & 24,30 & 34,62 & 17,10 & 86,85 & 105,85 & 17,30 & 58,31 & 112,72 & 23,33 & 13,18 & 42,30 & 24,52 & 70,74 & 27,20 & 74,53 & 76,64 & 31,43 & 12,87 \\
\hline 5 & 25,23 & 39,49 & 41,31 & 44,98 & & 29,56 & 15,93 & 49,33 & 54,96 & 41,97 & 21,78 & 35,95 & 30,39 & 60,44 & 107,19 & 28,39 & 59,64 & 114,05 & 38,79 & 34,87 & 8,77 & 21,19 & 37,70 & 35,99 & 75,86 & 77,98 & 32,76 & 34,56 \\
\hline$\frac{5}{6}$ & 9,33 & 10,10 & 65,19 & 15,59 & 23,88 & & 21,46 & 33,68 & 39,30 & 65,84 & 14,64 & 20,30 & 7.42 & 72,53 & 91,53 & 4,00 & 43,99 & 98,40 & 10,37 & 5,48 & 32,65 & 14,87 & 56,42 & 20,35 & 60,21 & 62,32 & 17,11 & 4,06 \\
\hline 7 & 12.78 & 27,04 & 43,90 & 32,53 & 259 & 17,11 & & 36,89 & 42,51 & 44,56 & 9 & 23,51 & 17 & 63.04 & 94,74 & 15 & 47,19 & 101,61 & 26 & 22 & 11 & 8. & 40,29 & 28.07 & & & & 22,12 \\
\hline 8 & 19 & 42,45 & 77,85 & 47,94 & 36,54 & 31,09 & 34,12 & & 43,87 & 62,09 & 27,30 & 13,07 & 28 & 55 & 96 & 30 & 48, & 102,97 & 41 & 37 & $4:$ & 27 & 39,34 & 38 & 64,77 & & & 37,52 \\
\hline 9 & 41,97 & 56,23 & 91,62 & 61,72 & 50,32 & 44,87 & 47,90 & 50,48 & & 92,28 & 41,08 & 37,10 & 41,79 & 89,33 & 61,72 & 44,51 & 16,01 & 68,58 & 55,53 & 51,61 & 59,09 & 41,30 & 73,23 & 51,91 & 30,39 & 50,95 & 32,47 & 51,30 \\
\hline 10 & 59,03 & 73,29 & 26,80 & 78,78 & 45,15 & 63,36 & 49,73 & 56,47 & 88,76 & & 55,58 & 58,97 & 64,19 & 45,50 & 140,99 & 62,19 & 93,44 & 147,86 & 72,59 & 68,67 & 42,58 & 54,99 & 22,75 & 69,79 & 109,66 & 79,52 & 66,57 & 68,37 \\
\hline 11 & 5,90 & 20,16 & 51,77 & 25,65 & 10,46 & 10,23 & 8,04 & 30,01 & 35,63 & 52,43 & & 16,63 & 11,06 & 68,85 & 87,86 & 9,06 & 40,31 & 94,73 & 19,47 & 15,54 & 19,22 & 1,86 & 48,15 & 15,84 & 56,53 & 58,65 & 13,44 & 15,24 \\
\hline 12 & 16,03 & 30,29 & 65,68 & 35,78 & 24,38 & 18,93 & 21,96 & 15,65 & 31,71 & 66,34 & 15,14 & & 15,85 & 54,49 & 83,94 & 18,57 & 36,39 & 90,81 & 29,59 & 25,67 & 33,15 & 15,36 & 38,39 & 25,97 & 52,61 & 44,29 & 6,65 & 25,36 \\
\hline 13 & 8,33 & 22,59 & 57,99 & 28,08 & 16,68 & 5,54 & 14,26 & 26,48 & 32,10 & 58,65 & 7,45 & 13,09 & & 65,32 & 84,33 & 5,56 & 36,78 & 91,20 & 21,90 & 17,97 & 25 & 7,67 & 49,22 & 18,27 & 53,00 & & 9,91 & 17,67 \\
\hline 14 & 66,52 & 80,78 & 80,64 & 86,26 & 62,79 & 69,42 & 72,44 & 48,89 & 82,20 & 45,49 & 65,63 & 51,39 & 66,34 & & 134,43 & 69,06 & 86,88 & 141,29 & 80 & 76 & 60 & 65,85 & 24,63 & 76,45 & 103,10 & 42,02 & 57,14 & 75.85 \\
\hline 15 & 85,62 & 99,88 & 135,28 & 105,37 & & 88,52 & 91,55 & 94,14 & 62,16 & 135,93 & 84,73 & 80,76 & 85,44 & 107,92 & & 88,16 & 90,49 & 58,23 & 99,19 & 95,26 & 102 & 84,96 & 116,88 & 95,56 & & 68 & 76,12 & 94,96 \\
\hline$\frac{16}{16}$ & 7,44 & 12,10 & 63,30 & 17,59 & 21 & 2,39 & 19,57 & 36,46 & 42,08 & 63,96 & 12,7 & 23,08 & 5,69 & 75,30 & 94, & & 46,76 & 101,18 & 11,41 & & 30 & 12,98 & 59,20 & 2140 & 62,98 & & & 7,18 \\
\hline$\frac{10}{17}$ & 40,85 & 55,11 & 90,51 & 17,91 & 49,20 & 43,75 & 46,78 & 49,37 & 16,0 & 91 & 39.97 & 35,99 & 40,67 & 88,22 & 92,12 & 43,41 & & 98,99 & 54,42 & 50,49 & 57 & 40 & 72 & 50 & 60 & 8 & 36 & 50,19 \\
\hline 18 & 95,40 & 109,66 & 145,06 & 115,15 & 103,75 & 98,30 & 101,33 & 103,92 & 71,94 & 145,71 & 94,5 & 90 & 95,22 & 117,70 & 57,54 & $\begin{array}{r}47,40 \\
97,95\end{array}$ & 100,27 & & $\begin{array}{r}0,42,97 \\
108\end{array}$ & $\begin{array}{r}105,04 \\
105\end{array}$ & 112 & 94,74 & 126,66 & 105 & 48,64 & & 85 & 104,74 \\
\hline 19 & 9,23 & 14,99 & 61,66 & 20,48 & 23,77 & 10,23 & 21,35 & 38,24 & 43,86 & 65,74 & 14 & 24,86 & 15,74 & 77,09 & 96,10 & 11,81 & 48,55 & 102,96 & & 10,37 & 32. & 14,76 & 60,98 & 10 & 64,77 & & 21,67 & 7,45 \\
\hline 20 & 14,30 & 5,8 & 70 & 11 & 28 & 6,02 & 26,43 & 43,32 & 48,94 & 70,81 & 19,63 & 29,93 & 10 & 82,16 & 101 & 12 & 53 & 108,04 & 9,6 & & 37,62 & 19,84 & 66,06 & 19 & 69,84 & 71,96 & 26,75 & 4,08 \\
\hline 21 & 29,31 & 43,57 & 33.27 & 49,06 & 15,43 & 33.64 & 20,01 & 53.42 & 59,04 & 33,93 & 25,86 & 40,04 & 34,47 & 52,41 & 111,27 & 32,48 & 63,73 & 118,14 & 42,88 & & & 25,28 & 29.67 & 40,08 & 79,95 & 82.06 & 36,85 & 38.65 \\
\hline 22 & 5,40 & 19,66 & 52,49 & 25,15 & 11,18 & 9,73 & 8,76 & 29,50 & 35,12 & 53,15 & 1,96 & 16,12 & 10,56 & 68,35 & 87,36 & 8,56 & 39 & 94,22 & 18,96 & 15,04 & 19,95 & & 48,88 & $\pi 1,42$ & 56,03 & 58,14 & 12,93 & 14,73 \\
\hline$\frac{23}{23}$ & $\begin{array}{r}5,40 \\
51,34\end{array}$ & $\begin{array}{r}15,000 \\
65,60\end{array}$ & $\begin{array}{l}32,40 \\
57,90\end{array}$ & $\begin{array}{l}20,110 \\
71,09\end{array}$ & $\begin{array}{l}1,10 \\
40,06\end{array}$ & 54,24 & $\begin{array}{l}0,10 \\
44,64\end{array}$ & $\begin{array}{l}23,70 \\
33,71\end{array}$ & $\begin{array}{l}3,112 \\
67,02\end{array}$ & 22,75 & $\begin{array}{r}1,30 \\
50,45\end{array}$ & $\begin{array}{l}10,012 \\
36,22\end{array}$ & 51 & $\begin{array}{l}0,035 \\
24,64\end{array}$ & 119,25 & 53 & 71 & $\begin{array}{l}34,6 \\
126 .\end{array}$ & 64,91 & 60 & $\begin{array}{l}17,50 \\
37,49\end{array}$ & 49,90 & & 64,70 & 87,92 & 56 & 12 & 60,68 \\
\hline 24 & 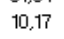 & 24,95 & 51,0 & 30,4 & & . & 30 & 39 & & 67. & 13 & 25 & 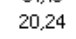 & & & 21 & . & 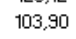 & & 20 & & +0 & 63 & & 65 & & & 17,41 \\
\hline 2 & & 70 & & & & & & 6 & & & 55 & & & & & 5 & & & & & & & & 66,6 & & & & 66,06 \\
\hline$\frac{20}{26}$ & & & & & & & & & & & & & & & & & & & & & & & & & & & $\begin{array}{l}4,20 \\
35,19\end{array}$ & 68,73 \\
\hline 27 & 13 & 27,46 & 62 & 32 & & 16. & 19 & 21,71 & 28 & & & 8, & & & & & & 81 & 26 & 22 & 30 & 12 & 44 & 23 & & & & 22,53 \\
\hline 28 & 11,34 & 8.88 & 67,20 & 14,37 & 25,89 & 5.09 & 23,47 & 40,36 & 45,98 & 67,86 & 16,67 & 26,98 & 11,32 & 79,21 & 98,21 & 8.2 & 50 & 105,08 & 6,9 & 4.2 & 34 & 16,8 & 63,10 & 16,95 & 66,89 & & & \\
\hline 29 & 63,74 & 77,99 & 31,51 & 83,48 & 49,85 & 68,06 & 54,43 & 73,15 & 93,46 & 26,64 & 60,28 & 74,46 & 68,89 & 62,17 & 145,69 & 66,90 & 98,15 & 152,56 & 77,30 & 73,37 & 47,28 & 59,70 & 39,43 & 74,50 & 114,37 & 96,20 & 71,27 & 3.07 \\
\hline
\end{tabular}

Fonte: Autora (2018) 
Com os dados coletados referentes ao deslocamento entre as 29 subestações, foi possível elaborar o modelo matemático bem como a interface no Microsoft Excel. Essa interface permitiu sequenciar a rota pré-estabelecida visando otimizar a distância percorrida.

\section{FORMULAÇÃO MATEMÁTICA}

De acordo com Souza (2009), quando assume-se o grafo $G=$ (Cidades; $A$ ), pode-se obter a seguinte formulação matemática:
(a) Conjuntos
C: Conjunto de cidades (clientes)

(b) Dados

$\mathrm{d}_{\mathrm{ij}}$ : Distância da cidade i para a cidade $j$

(c) Variáveis de decisão:

$\mathrm{x}_{\mathrm{ij}}:\left\{\begin{array}{l}1, \text { se o } \operatorname{arco}(i ; j) \text { for utilizado } \\ 0, \text { caso contrário }\end{array}\right.$

$\mathrm{f}_{\mathrm{ij}}$ : quantidade de fluxo enviada da cidade i para a cidade $j$

(c) Função objetivo

$\min \sum_{i \in \text { Cidades }} \sum_{j \in \text { Cidades }} d_{i j} x_{i j}$

(d) Restrições

$\sum_{i \in \text { Cidades }} x_{i k}=1 \forall k \in$ Cidades

$\sum_{J \in \text { Cidades }} x_{k j}=1 \forall k \in$ Cidades 
$\sum_{i \in \text { Cidades }} f_{i k}-\sum_{j \in \text { Cidades }} f_{k j}=1 \forall k \in$ Cidades $\mid k \neq 1$

$f_{i j} \leq(n-1) x_{i j} \forall i \in$ Cidades, $\forall j \in$ Cidades

$x_{i j} \in\{0,1\} \forall i \in$ Cidades, $\forall j \in$ Cidades

$f_{i j} \geq 0 \quad \forall i \in$ Cidades, $\forall j \in$ Cidades

A equação (1) que representa a função objetivo deixa claro que a minimização das distâncias percorridas é o foco principal desse problema.

Entretanto, existem restrições que são essenciais, como por exemplo, as equações (2) e (3) que garantem que a cada cidade k só chegue um arco, e de que cada cidade k só saia um arco.

As restrições (4) e (5) garantem a eliminação dos subciclos. Na primeira delas, impõe-se que o fluxo que chega a uma cidade $k$ menos o que sai de $k$ seja igual a 1 (exceto para a cidade origem, cujo índice é 1).

Já na segunda, o fluxo máximo que passa em um arco usado no percurso é inferior a $\mathrm{n}-1$, onde $\mathrm{n}$ é o número de cidades, e quando um arco não é usado (xij = 0) então o fluxo é nulo (SOUZA, 2009).

\section{CARACTERIZAÇÃO DO PROBLEMA}

O estudo de caso foi realizado em uma concessionária de energia elétrica localizada no Brasil. O processo existente é formado por subsistemas (as equipes de manutenção das subestações) que ao trabalharem e interagirem de forma eficiente garante a funcionalidade do mesmo. Assim, o processo de manutenção em uma concessionária de energia elétrica pode ser considerado um sistema como sendo "[...] um conjunto de partes interagentes e interdependentes, que formam um todo unitário com determinado objetivo e efetuam determinada função" (ALMEIDA, 2011, p. 15). Este sistema é composto por subestações, linhas de transmissões, usinas, unidades 
consumidoras e outros elementos relevantes, culminando na geração e transmissão de energia elétrica. E pode ser classificado com um sistema físico, pois, são compostos de equipamentos, máquinas objetos e coisas reais e também sistemas abertos, pois apresentam relações de intercâmbio com o ambiente por meio de inúmeras entradas e saídas.

Analisando a concessionária como um sistema conforme a Figura 05, podemse observar como inputs os equipamentos, peças, ferramentas, veículos de transporte, componentes da equipe e conhecimento. Posteriormente, essas entradas são processadas e auxiliam na execução dos serviços em subestações. Por fim, obtêm-se as saídas, que se apresentam na forma de serviço finalizado ou não.

Figura 5 - Esquema conceitual de um sistema

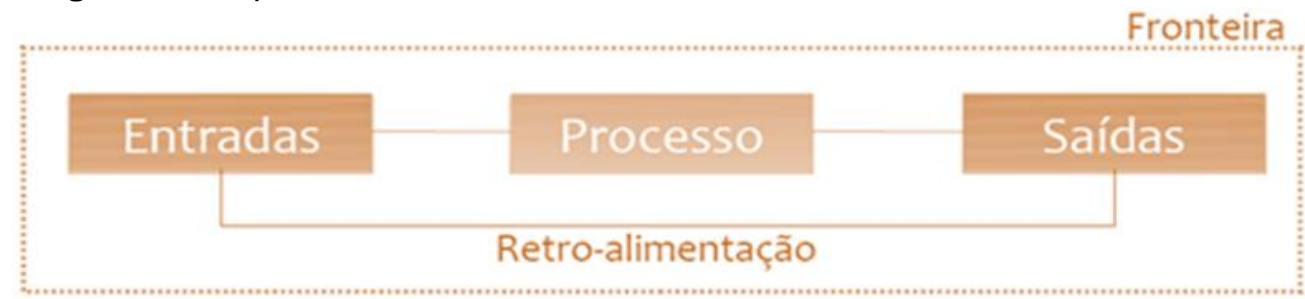

Fonte: Autora (2018)

Os subsistemas são representados pelas equipes de manutenção, que são consideradas a peça chave no processo, pois são responsáveis diretas pelos resultados obtidos nos indicadores de desempenho. Entre esses indicadores encontram-se a produtividade da equipe, tempo de deslocamento e entre outros.

A Figura 6 representa o fluxograma, onde se observa que o deslocamento de saída da base (sede), bem como o deslocamento entre as subestações é considerado desvio, contribuindo para uma diminuição do tempo produtivo, refletindo no não alcance de metas internas referentes à produtividade de equipes.

A disponibilidade individual de cada colaborador da equipe, refere-se a uma jornada de trabalho de 8 horas diárias, durante os 5 dias úteis da semana, isentandose do horário do almoço, totalizando 40 horas semanais. Logo, a disponibilidade total corresponde ao somatório da disponibilidade de cada componente da equipe.

As equipes formadas por quatro pessoas em um único carro, diariamente saem da sede e devem visitar todas as subestações que constam na sua ordem de trabalho 
e voltar para a sede. Considera-se que as equipes não possuem um número limitado de serviços para executarem nas subestações, mas a média por dia de visitas em subestações varia de 5 a 10 clientes, possuindo um total de 29 clientes.

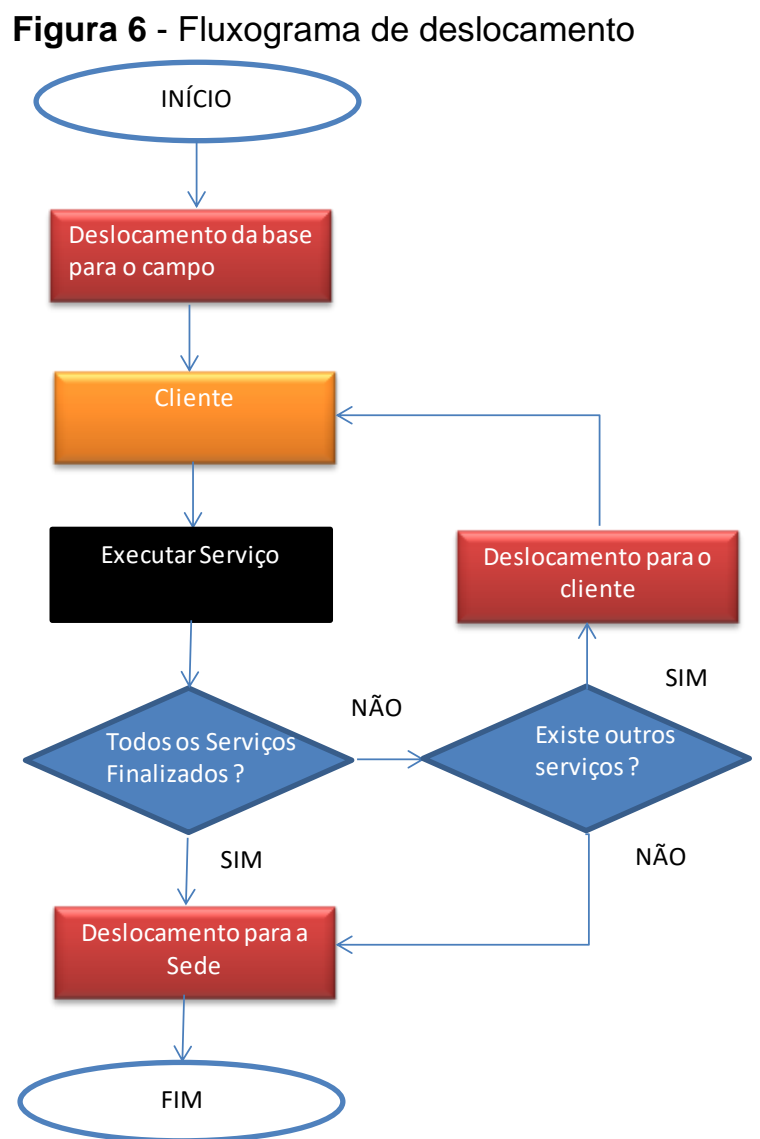

Fonte: Autora (2018)

Atualmente na organização a determinação das rotas é feita prioritariamente baseada no conhecimento tácito do programador. Como instrumentos auxiliares, ele utiliza a cartografia, e vários tipos de mapas. Dessa forma, observa-se uma grande deficiência nesse processo que pode resultar em rotas imprecisas, e consequentemente deslocamentos maiores.

Diante desse cenário e com a finalidade de verificar o impacto da diminuição dos deslocamentos na produtividade das equipes de manutenção, utilizou-se a Pesquisa Operacional (PO) na busca pela otimização das rotas. De forma indireta essa otimização contribuiria para que as equipes pudessem ser alocadas em outras atividades que também agregassem valor ao processo. 


\section{METODOLOGIA DE RESOLUÇÃO}

Para possibilitar a resolução do problema, ou seja, minimizar as distâncias utilizou-se a biblioteca integrada chamada de UFFLP no solver que acompanha a Microsoft Excel. Em um primeiro momento foi necessário criar uma matriz de distâncias mínimas de deslocamento com o auxílio do Google Maps. Essa primeira matriz foi criada para que fossem introduzidas as distâncias das 29 subestações. Posteriormente o usuário indicava na interface do Excel as cidades que ele desejava criar uma rota. Essa indicação gerava outra matriz, que era lida pelo programa e gerava a rota com a menor distância percorrida.

Por fim, para avaliar o impacto da otimização fez-se uma comparação entre o resultado obtido e o gerado pelo programador. Ou seja, escolheram-se três rotas feitas na última semana por uma equipe e que foi sequenciada de forma manual, e comparou-se com o resultado gerado pelo modelo de programação.

As figuras seguintes representam uma rota qualquer, cujo objetivo é mostrar a metodologia de resolução. A Figura 7 representa a linguagem computacional adotada.

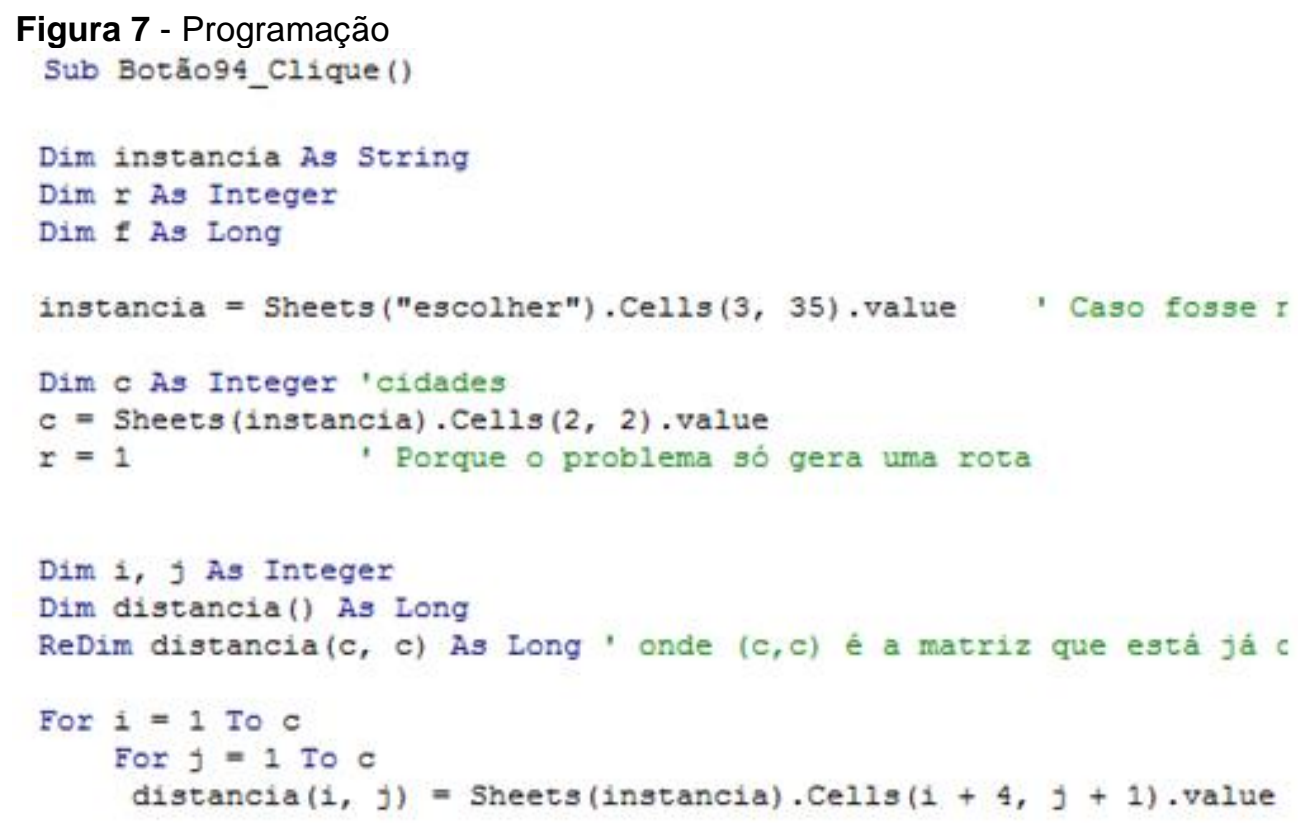

Fonte: Autora (2018)

A Figura 8 representa 0 arquivo .lp, que expõe o resultado gerado com a solução do problema. 


\section{Figura 8 - Arquivo .lp}

Solution LOG:

f_1_3 = 4

f_2_4 $=2$

f_3 2 - $=3$

$f-4+5=1$

$x_{-}{ }_{1} 3=1$

x_2_4 = 1

$x_{-}{ }_{3}-2=1$

x_4_5 $=1$

x_5_1 = 1

Fonte: Autora (2018)

A Figura 9 representa a interface criada na planilha do Excel, no qual possui botões que executam a programação do VBA, posteriormente aparece uma mensagem se a solução ótima foi encontrada ou não.

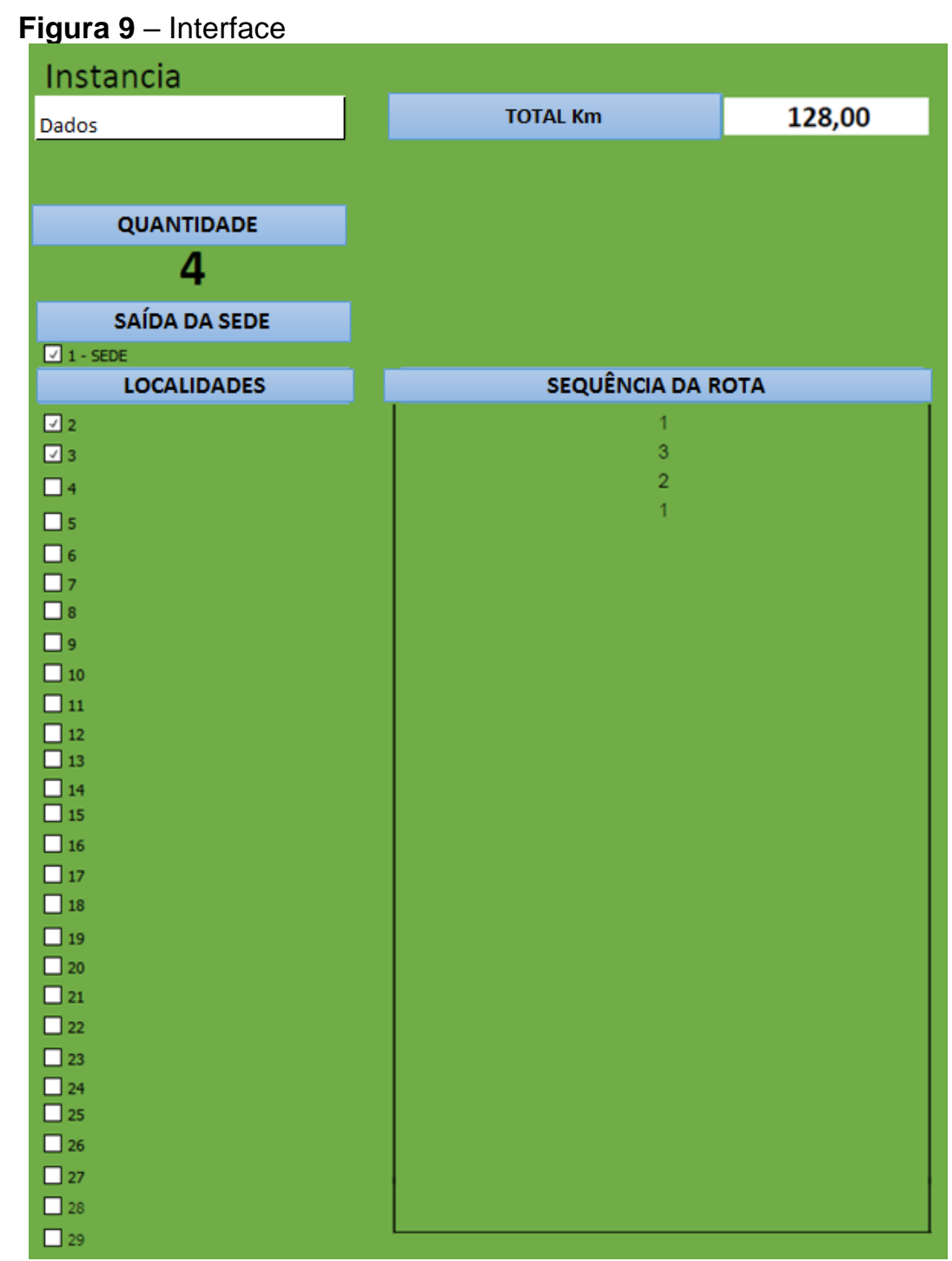

Fonte: Elaboração pela autora por meio do Excel 2010

Revista Produção Online. Florianópolis, SC, v. 20, n. 1, p. 221-246, 2020 


\section{RESULTADOS}

Foram coletadas 3 rotas realizadas anteriormente no setor realizadas com um veículo Volkswagen Amarok, que utiliza como combustível o óleo diesel S10 (Tomou como base a média de valor do óleo diesel correspondente a $R \$ 3,05)$, tem consumo médio de $8,8 \mathrm{~km} / \mathrm{I}$ na cidade e é ocupado por 4 técnicos. No qual foram entregues as sequências das subestações para que pudessem seguissem a rota proposta pelo profissional responsável por realizar a programação de serviços do setor. Porém, o setor leva em consideração o total de deslocamento, prioridade de serviços e prazo a ser cumprido.

O nosso primeiro cenário de sequenciamento da rota proposto pelo setor à equipe correspondeu: $1 \rightarrow 22 \rightarrow 18 \rightarrow 3 \rightarrow 23 \rightarrow 25 \rightarrow 26 \rightarrow 9 \rightarrow 1$. A rota adotada resultou em $522 \mathrm{Km}, 8$ horas, 2 minutos totalizados pelo Google Maps. E a tabela 2 representa o resultado obtido utilizando a modelagem do caixeiro viajante, com uma redução de $160 \mathrm{~km}$, ou seja, $30,6 \%$ no percurso percorrido.

Tabela 2 - Resultados rota 1

\begin{tabular}{ccc}
\hline ROTA 01 ATUAL & $\begin{array}{c}\text { ROTA 01 } \\
\text { PROPOSTA }\end{array}$ \\
\hline & 1 & 1 \\
& 22 & 9 \\
& 18 & 25 \\
& 3 & 18 \\
& 23 & 26 \\
& 25 & 23 \\
& 26 & 18 \\
Distância & 9 & 9 \\
Total: & 1 & 1 \\
\hline
\end{tabular}

Fonte: Autora (2018)

O segundo cenário de sequenciamento de rota proposto pelo setor à equipe, é similar a rota 01 , diferenciando apenas a existência do cliente 21 , logo correspondeu: $1 \rightarrow 21 \rightarrow 18 \rightarrow 3 \rightarrow 23 \rightarrow 25 \rightarrow 26 \rightarrow 9 \rightarrow 1$. A rota adotada resultou $564 \mathrm{~km}$, 8horas, 28 minutos totalizados pelo Google Maps. Mediante a tabela 3, o resultado obtido utilizando a modelagem do caixeiro viajante, com uma redução de $192 \mathrm{Km}$, ou seja, 34,04\% no percurso percorrido 
Tabela 3 - Resultados rota 2

\begin{tabular}{ccc}
\hline & $\begin{array}{c}\text { ROTA 02 } \\
\text { ATUAL }\end{array}$ & $\begin{array}{c}\text { ROTA 02 } \\
\text { PROPOSTA }\end{array}$ \\
\hline & 1 & 1 \\
& 21 & 21 \\
& 18 & 3 \\
& 3 & 23 \\
& 23 & 26 \\
& 25 & 25 \\
& 26 & 18 \\
Distância & 9 & 9 \\
Total: & 1 & $372 \mathrm{Km}$
\end{tabular}

Fonte: Autora (2018)

O nosso terceiro e último cenário de sequenciamento de rota proposto pelo setor à equipe correspondeu: $1 \rightarrow 19 \rightarrow 27 \rightarrow 4 \rightarrow 26 \rightarrow 1$. A rota adotada resultou $202 \mathrm{~km}, 3$ horas, 34 minutos totalizados pelo Google Maps. Mediante a tabela 4, o resultado obtido utilizando a modelagem do caixeiro viajante, com uma redução de $46 \mathrm{Km}$, ou seja, $22,77 \%$ no percurso percorrido.

Tabela 4 - Resultados rota 3

\begin{tabular}{ccc}
\hline $\begin{array}{c}\text { ROTA 03 } \\
\text { ATUAL }\end{array}$ & $\begin{array}{c}\text { ROTA 03 } \\
\text { PROPOSTA }\end{array}$ \\
\hline & 1 & 1 \\
& 19 & 19 \\
& 27 & 4 \\
& 4 & 26 \\
& 26 & 27 \\
Distância & 1 & 1 \\
Total: & $202 \mathrm{Km}$ & $156 \mathrm{Km}$ \\
\hline Fonte: Autora (2018) &
\end{tabular}

Portanto, a modelagem proposta através da introdução de restrições, não permitiu subciclos e disponibilizou uma solução ótima referente às cidades estabelecidas representadas pelos nós. Cujo modelo proposto não permite passar pela mesma cidade duas vezes, porem estabelece-se que deve sair da base e retornar ao final do percurso. 
No final dos três cenários citados anteriormente, o total de distância percorrida pelas equipes mediante a rota emitida pelo VBA foi menor, obtendo uma redução de considerável da distância total a ser percorrida, contribuindo para diminuição de despesas. Logo, observa-se o total de tempo desperdiçado em deslocamento improdutivo poderia ser aproveitado de forma bastante satisfatória.

Na tabela 5, tomando como base a rota de número 1, com o intuito de mostrar o total economizado obtêm-se então os seguintes dados:

Tabela 5 - Resultados rota 1

\begin{tabular}{ccccc}
\hline $\begin{array}{c}\text { Quilometragem } \\
\text { reduzida }(\mathrm{Km})\end{array}$ & $\begin{array}{c}\text { Consumo } \\
\text { Médio } \\
\text { (Km/Litros) }\end{array}$ & $\begin{array}{c}\text { Total de Diesel } \\
\text { economizado } \\
\text { (Litros) }\end{array}$ & $\begin{array}{c}\text { Preço do } \\
\text { Diesel utilizado }\end{array}$ & $\begin{array}{c}\text { Total } \\
\text { economizado }\end{array}$ \\
\hline 160 & 8,8 & 18,18 & $\mathrm{R} \$$ & $\mathrm{R} \$$ \\
& & & 3,05 & 55,40
\end{tabular}

Tempo reduzido Custo Homem- Total economizado (Minutos) hora (Equipe composta por 4 pessoas)

$122 \quad 8,30 \quad 58,80$

$\mathrm{R} \$$

Redução média na rota 01: $\quad 114,20$

Fonte: Autora (2018)

\section{CONCLUSÕES}

Através do tratamento e posteriormente análise dos dados, foi possível demonstrar qual foi à rota traçada pela concessionária e qual seria a melhor rota para a equipe ter realizado através do modelo do caixeiro viajante.

A incorporação da programação em VBA permitiu uma interface de fácil manuseio e que com apenas um clique no botão geraria uma rota ótima. Essa ferramenta não traria custos adicionais para concessionária, pois o Microsoft Excel, o VBA e o UFFLP podem ser utilizados de forma gratuita. A programação permitiu inúmeras combinações entre o conjunto de cidades, sendo a partida e a chegada o mesmo ponto (sede). Outro ponto que chamou atenção foi o tempo de resolução do problema, que durou menos de 1 segundo.

Foi possível observar que com a utilização da programação semanal da forma atual, realizada de forma manual, a organização continuará de forma constante a 
adquirir perdas ao processo. Entretanto, se for utilizado à interface desenvolvida nesse trabalho, a organização terá um melhor monitoramento das equipes, e uma diminuição de custos com a redução dos deslocamentos.

Por fim afirma-se que as sequências de rotas disponibilizadas pela modelagem foram totalmente satisfatórias, mediante a disponibilização de informações para comparar os cenários. Com a intenção de implementar estratégias que visam aproveitar da melhor forma possível o tempo disponível das equipes, podem ser citados como tópicos a serem trabalhados posteriormente desde a prioridade de serviço, atribuindo pesos, tempo disponível total da equipe de forma semanal ou diária, tempo de setup entre serviços, tempo de almoço e prazo estipulado do serviço.

\section{REFERÊNCIAS}

ABNT - ASSOCIAÇÃO BRASILEIRA DE NORMAS TÉCNICAS. NBR ISO-8402, Gestão da qualidade e garantia - Terminologia. Rio de Janeiro: ABNT, 1994.

ABNT - ASSOCIAÇÃO BRASILEIRA DE NORMAS TÉCNICAS. NBR 5462, Confiabilidade e mantenabilidade - Rio de Janeiro: ABNT, 1994.

AIOSA, R. O que é VBA? São Paulo, 2011. Disponível em:

http://www.escolaexcel.com.br/2011/08/o-que-e-vba.html. Acesso em: 19 out. 2018.

ANNEL - AGÊNCIA NACIONAL DE ENERGIA ELÉTRICA. Atlas de energia elétrica do Brasil (AEEB). 3. ed. - Brasília: Aneel, 2008.

ARENALES, M.; ARMENTANO, V.; MORABITO, R.; YANASSE, H. Pesquisa operacional para cursos de engenharia. Editora Campus, 2007.

ALMEIDA, Mário de Souza. FREITAS, Claudia Regina. SOUZA, Irineu Manoel de. Gestão do conhecimento para tomada de decisão. São Paulo: Atlas, 2011.

CAIXEIRO. Disponível em: http://www.mat.ufrgs.br/ portosil/caixeiro.html. Acesso em: 08 set. 2018.

COELHO, Leandro Callegari. Série pesquisa operacional: problema de roteamento de veículos. 2010. Disponível em: https://www.logisticadescomplicada.com/serie-pesquisaoperacional-\%E2\%80\%93-problema-de-roteamento-de-veiculos/ . Acesso em: 17 nov. 2018.

GAPSON Analytics. UFFLP. 2018. Disponível em: http://www.gapso.com.br/ufflp/. Acesso em: 17 jan. 2018

LACHTERMACHER, Gerson. Pesquisa operacional na tomada de decisões: modelagem em excel. Rio de Janeiro. Elsevier, 2007.

MANGUINO, João Luiz Veiga. Problema de roteamento de veículo com frota mista, janelas de tempo e custos escalonados. 2013. 88 f. Dissertação (Mestrado) - Curso de 
Mestrado em Engenharia, Escola Politécnica da Universidade de São Paulo, São Paulo, 2013.

MAPS. Google. Disponível em: https://www.google.com.br/maps. Acesso em: 09 de set. 2018.

MARQUES, G. M. et al. Aplicação da programação dinâmica na substituição de equipamentos. Revista Árvore, 2005. https://doi.org/10.1590/S0100-67622005000500010

MARTINS, Petr nio G.; LAUGENI, Fernando P. Administração da produção. 3.ed. São Paulo:Saraiva, 2015.

PARANHOS, F. Inserindo um marcador com comando VBA. Rio Grande do Sul, 2012. Disponível em:https://www.aprenderexcel.com.br/2013/vba/inserindo-um-marcador-comcomando-vba. Acesso em: 17 nov. 2018.

PISINGER, D. \& ROPKE, S. A general heuristic for vehicle routing problems. Computers \& Operations Research, 2007 https://doi.org/10.1016/j.cor.2005.09.012

Plataforma UFFLP. Integrando programação inteira mista e planilhas de cálculo de forma simples e acessível. Disponível em: http://www.gapso.com.br/ufflp/. Acesso em: 17 nov. 2018.

SALES et al. Qualidade do fornecimento de energia elétrica: confiabilidade, conformidade e presteza. Revista GTD. 2014. Disponível em:

http://www.acendebrasil.com.br/media/artigos/20141125 RevistaGTD1 Qualidadedoforneci mentodenergiaeletricaconfiabilidadeconformidadeepresteza.pdf. Acesso em: 09 nov. 2018.

SIQUEIRA, Paulo Henrique. Uma nova abordagem na resolução do problema do caixeiro viajante. Curitiba, 2005. Disponível em:

https://www.acervodigital.ufpr.br/bitstream/handle/1884/2562/paulohsTese.pdf? sequence=1. Acesso em: 19 nov. 2018.

SOUZA. Marcone Jamilson Freita. Otimização Combinatória. Apostila. 2009. Disponível em:http://www.decom.ufop.br/marcone/Disciplinas/OtimizacaoCombinatoria/OtimizacaoCom binatoria.pdf. Acesso em: 10 nov. 2018.

TAVARES, Romero. Construindo mapas conceituais. Ciências \& Cognição, v. 4, n. 12. Disponível em:

http://www.fisica.ufpb.br/ romero/objetosaprendizagem/Rived/Artigos/2007ConstruindoMC.p df. Acesso em: 12 nov. 2018.

TOTH, P. \& VIGO, D. The vehicle routing problem. SIAM, 2002.

https://doi.org/10.1137/1.9780898718515

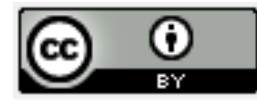

Artigo recebido em: 08/01//2019 e aceito para publicação em: 04/03/2020

DOI: http://dx.doi.org/10.14488/1676-1901.v20i1.3491 